\title{
Administrative Law and Sustainable and Inclusive Technologies in Face of the Hunger Pandemic
}

\section{Antik A*}

Administrative Law Professor, National University of Rosario, Argentina

*Corresponding author: Analía Antik, Administrative Law professor, Academic Secretary in the Public Law Master Program and of the Administrative Law Research Center (CIDeA, in Spanish) of the Universidad Nacional de Rosario's Law School, Researcher of the Research

Council of the Universidad Nacional de Rosario, Coordinator of the Research Axis of the Euro-Latin American Administrative Law Teaching Network (REDOEDA, in Spanish), Argentina, Email: aantik@fder.unr.edu.ar

\section{Mini Review}

\section{Introduction}

The United Nations (UN) is alerting about a hunger pandemic, far worse than COVID-19, because an increasing amount of people lack access to enough nutritious food [1].

The Regional Director of the United Nations World Food Programme for Latin America and the Caribbean warned that "if the tendency does not change, the possibility of achieving the zero hunger goal of the Sustainable Development Goals will move away" [2].

The lack of access to enough nutritious food means talking about an indigent population, i.e., people that is not even considered as of poor condition. For several years now, our research team at Universidad Nacional de Rosario has been dedicated to studying the scourge of social exclusion, addressing topics that go from the signifying of various legal categories, such as public contracts, to the organization and management of government bodies, public urban development policies, respect for the environment and the use of sustainable and inclusive technologies to improve state management in its relationship with the people.

\section{Intelligent Public Administration (IPA) to Face Social Issues}

The tragedy of exclusion requires radical transformation of government administrations the subject matter of Administrative Law of its bureaucracy [3], of the use of materials and human resources, of the formulation of public policies, and of the accountability, in short, an urgent and complete turnabout.

The 4.0 revolution must come along with sustainable and inclusive technologies.

What are sustainable technologies and how do they connect with the Administrative Law?

A technology shall be considered sustainable when it is capable of solving social issues for the current and future generations. It is inevitable to understand that the question of technology does not exhaust itself in mere tools which improve procedures, organizational structures or a change of support in the externalization of the will of the administration, but that when we refer to intelligent public administration, we need to ask ourselves the following questions:

- Can the classical Weberian bureaucratic organization hold on?

- Is it just about de-papering formalities?

- Do machines replace humans?

- Is there a right to intelligent public administration?

- What happens with the digital divide and the biases which appear when using algorithms?

The ECLAC sets forth the important of technology sustainability for solving problems and that the advancement of the region in the next years will depend on rapidly reducing three types of divides [4]:

- The infrastructure divide, linked to access and to the quality of broadband. 
- The complementary assets divide linked to the lack of human resources, business management, and research and development.

- The institutional divided linked to weaknesses in the design of public policies, in the organization of programs, in the coordination of key actors and in the availability of resources.

The API does not depend on new techniques but on new knowledge for the collaborative creation of solutions. When we talk about sustainable technologies we refer to inclusive and democratic technologies that require the fundamental rights to become a key component in the sphere of data and the ethics of artificial intelligence, which is experiencing exponential growth.

According to the "Carta Iberoamericana de Innovación en la Gestión Pública" [5], the intelligent public administration implies data extraction, analysis and interpretation, not only at technological level (by means of algorithms and algorithm training systems), but also at human knowledge level (collective intelligence systems both inside and outside the Administration), to allow the proactive detection of new social and individual needs for renewing and updating the public services catalogues and the internal management systems with the purpose of providing greater social welfare.

This brings forth a concept that calls for true transformation: "collective intelligence", which is the universally distributed, constantly valued, and coordinated in real-time intelligence that leads to an effective mobilization of competencies, whose objective is mutual recognition and enrichment of individuals and groups to reach specific objectives. The new technologies have caused a major revolution in collective intelligence. It is impossible for all of us to master broad areas of knowledge, but we can be experts in specific areas, and thanks to the new technologies we can bring together all those microknowledges to create a collective intelligence.

\section{Conclusion}

An API implies a democratic, inclusive, open and transparent relational model.

For the model to be democratic and inclusive it is necessary to promote actions that tend to democratize the access to technology and decrease the technological divide, to allow the historically excluded groups to access the products and services of a renewed public administration [6].

Block-chain is one of the technologies that allow collaborative work. Its name implies a distributed ledger that enables recording public data to offer greater transparency and safety, because anyone can verify that said data is not modified. Instead of using state storage, block-chain uses decentralized cloud storage which is accessed by fingerprint or token.

Today, dialog between the Administrative Law and the sustainable and inclusive technologies is not an option but a need for building consensus to allow overcoming the severe social crisis in which we are immersed.

\section{References}

1. Negocios B (2020) The UN alerts that Coronavirus will become a "hunger pandemic". Latin America.

2. Goal 1: End poverty in all its forms everywhere.

3. (2020) Due to COVID-19 pandemic, the number of persons that live in extreme poverty will increase in 150 million.

4. Economic Commission for Latin America and the Caribbean.

5. (2020) Agreement of Ministers subscribed in Andorra.

6. Idem.

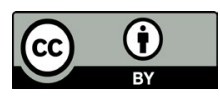

